This item was submitted to Loughborough's Research Repository by the author.

Items in Figshare are protected by copyright, with all rights reserved, unless otherwise indicated.

\title{
Mindfulness training and employee well-being
}

PLEASE CITE THE PUBLISHED VERSION

http://dx.doi.org/10.1108//JWHM-11-2014-0049

\section{PUBLISHER}

Emerald / @ Crown Copyright.

\section{VERSION}

AM (Accepted Manuscript)

\section{PUBLISHER STATEMENT}

This work is made available according to the conditions of the Creative Commons Attribution-NonCommercialNoDerivatives 4.0 International (CC BY-NC-ND 4.0) licence. Full details of this licence are available at: https://creativecommons.org/licenses/by-nc-nd/4.0/

\section{LICENCE}

CC BY-NC-ND 4.0

\section{REPOSITORY RECORD}

Mellor, N., L. Ingram, M. Van Huizen, John Arnold, and A-H. Harding. 2019. "Mindfulness Training and Employee Well-being". figshare. https://hdl.handle.net/2134/20899. 


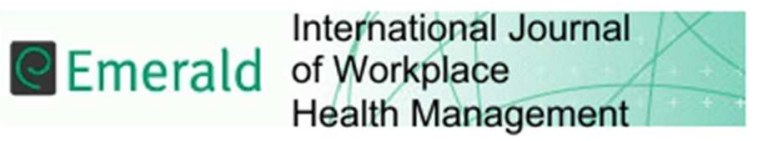

\section{Mindfulness Training and Employee Well-being}

\begin{tabular}{|r|l|}
\hline Journal: & International Journal of Workplace Health Management \\
\hline Manuscript ID & IJWHM-11-2014-0049.R3 \\
\hline Manuscript Type: & Research Paper \\
\hline Keywords: & Evaluation, Mindfulness, Training , Controlled study \\
\hline \multicolumn{2}{|c}{} \\
\hline
\end{tabular}

\section{SCHOLARONE ${ }^{\text {m }}$ \\ Manuscripts}




\begin{tabular}{|c|c|c|c|c|c|c|}
\hline \multirow[t]{2}{*}{ Scale/subscale } & \multicolumn{2}{|c|}{ Control Group } & \multicolumn{2}{|c|}{$\begin{array}{l}\text { Mindfulness } \\
\text { Training }\end{array}$} & \multicolumn{2}{|c|}{ Total } \\
\hline & Mean & SD & Mean & SD & Mean & SD \\
\hline \multicolumn{7}{|l|}{ Mindfulness Skills (KIMS) } \\
\hline Observing T1 & 37.0 & 8.8 & 34.2 & 7.7 & 35.5 & 8.2 \\
\hline Observing $\mathrm{T} 2$ & 39.6 & 9.1 & 43.2 & 6.5 & 41.5 & 7.9 \\
\hline Observing T3 & 40.5 & 8.0 & 43.3 & 7.8 & 42.0 & 7.8 \\
\hline Describing $\mathrm{T} 1$ & 29.4 & 4.6 & 23.7 & 4.8 & 26.4 & 5.4 \\
\hline Describing T2 & 30.4 & 4.2 & 27.3 & 4.7 & 28.7 & 4.7 \\
\hline Describing T3 & 30.0 & 5.8 & 28.7 & 4.5 & 29.3 & 5.1 \\
\hline Acting with Awareness T1 & 31.6 & 5.1 & 25.8 & 5.3 & 28.5 & 5.9 \\
\hline Acting with Awareness T2 & 31.2 & 5.2 & 33.0 & 6.0 & 32.2 & 5.6 \\
\hline Acting with Awareness T3 & 31.0 & 5.4 & 32.6 & 4.2 & 31.8 & 4.8 \\
\hline $\begin{array}{l}\text { Accepting without } \\
\text { Judgement } \mathrm{T} 1\end{array}$ & 32.7 & 3.6 & 29.6 & 6.7 & 31.1 & 5.6 \\
\hline $\begin{array}{l}\text { Accepting without } \\
\text { Judgement } \mathrm{T} 2\end{array}$ & 34.5 & 3.0 & 33.4 & 6.6 & 33.9 & 5.1 \\
\hline $\begin{array}{l}\text { Accepting without } \\
\text { Judgement T3 }\end{array}$ & 34.4 & 3.9 & 35.5 & 5.9 & 35.0 & 5.0 \\
\hline \multicolumn{7}{|l|}{ Wellbeing } \\
\hline Satisfaction with life $\mathrm{T} 1$ & 22.6 & 7.0 & 17.9 & 7.1 & 20.1 & 7.3 \\
\hline Satisfaction with life T2 & 24.6 & 5.8 & 23.0 & 7.2 & 23.8 & 6.5 \\
\hline Satisfaction with life T3 & 24.6 & 5.9 & 23.8 & 7.7 & 24.2 & 6.7 \\
\hline Anxiety (BAI) T1 & 9.8 & 4.5 & 14.2 & 7.9 & 12.1 & 6.7 \\
\hline Anxiety (BAI) T2 & 7.2 & 5.1 & 6.9 & 5.9 & 7.0 & 5.4 \\
\hline Anxiety (BAI) T3 & 7.6 & 5.2 & 9.6 & 6.7 & 8.7 & 6.0 \\
\hline Hope T1 & 5.8 & 1.2 & 4.8 & 1.0 & 5.3 & 1.2 \\
\hline Hope T2 & 5.8 & 1.0 & 5.8 & 1.2 & 5.8 & 1.1 \\
\hline Hope T3 & 5.9 & 1.1 & 6.1 & 1.0 & 6.0 & 1.0 \\
\hline
\end{tabular}

Note: KIMS=Kentucky Inventory of Mindfulness Skills. BAI $=$ Beck Anxiety Inventory Control Group $\mathrm{N}=11$, Mindfulness Training Group $\mathrm{N}=12$, Total $\mathrm{N}=23$

Table 1 Descriptive Statistics (means and standard deviations) 


\begin{tabular}{|c|c|c|c|c|c|c|c|c|c|}
\hline \multirow[b]{3}{*}{ Scale/Subscale } & \multirow{3}{*}{$\begin{array}{l}\text { Time } \\
\mathrm{F}_{2,42}\end{array}$} & \multirow{3}{*}{$\begin{array}{l}\text { Condition } \\
\qquad F_{1,21}\end{array}$} & \multirow{3}{*}{$\begin{array}{l}\text { Interaction } \\
\mathrm{F}_{2,42}\end{array}$} & \multicolumn{6}{|c|}{ Interaction Contrasts } \\
\hline & & & & \multicolumn{3}{|c|}{$\mathrm{T} 2-\mathrm{T} 1$} & \multicolumn{2}{|c|}{$\mathrm{T} 3-\mathrm{T} 2$} & \multirow[b]{2}{*}{$\begin{array}{l}\text { Differen } \\
\text { ces in } \\
\text { means }\end{array}$} \\
\hline & & & & $\mathrm{F}_{1,21}$ & $\mathrm{r}^{*}$ & $\begin{array}{l}\text { Differen } \\
\text { ces in } \\
\text { means }\end{array}$ & $\mathrm{F}_{1,21}$ & $\mathrm{r}^{*}$ & \\
\hline \multicolumn{10}{|l|}{$\begin{array}{l}\text { Mindfulness Skills } \\
\text { (KIMS) }\end{array}$} \\
\hline Observing & $16.23 * *^{\dagger}$ & 0.16 & $4.04 *^{\dagger}$ & $8.90 * *$ & .55 & 6.4 & 0.11 & .07 & -0.8 \\
\hline Describing & $11.54 * * *$ & 3.28 & $6.18 * *$ & 3.81 & .39 & 2.6 & 2.74 & .34 & 1.8 \\
\hline $\begin{array}{l}\text { Acting with } \\
\text { Awareness }\end{array}$ & $11.48 * * *$ & 0.15 & $14.74 * * *$ & $21.30 * * *$ & .71 & 7.6 & 0.07 & .06 & -0.2 \\
\hline $\begin{array}{l}\text { Accepting without } \\
\text { Judgement }\end{array}$ & $17.18 * * *$ & 0.24 & $5.13 * *$ & 2.88 & .35 & 2.0 & 4.02 & .40 & 2.2 \\
\hline \multicolumn{10}{|l|}{ Wellbeing } \\
\hline Satisfaction with Life & $19.98 * * *$ & 0.74 & $4.17 *$ & $5.69 *$ & .46 & 3.1 & 0.43 & .14 & 0.8 \\
\hline Anxiety (BAI) & $7.49 * *$ & 1.00 & 1.56 & $4.48^{*}$ & .42 & -4.7 & 0.66 & .17 & 2.3 \\
\hline Hope & $9.76^{*}$ & 0.19 & $5.46^{* *}$ & $5.52 *$ & .46 & 1 & 0.14 & .08 & 0.2 \\
\hline
\end{tabular}

Note: KIMS=Kentucky Inventory of Mindfulness Skills. BAI= Beck Anxiety Inventory

Control $\mathrm{N}=11$, Trainee $\mathrm{N}=12$, Total $\mathrm{N}=23 . * \mathrm{p}<.05 * * \mathrm{p}<0.01 * * * \mathrm{p} \leq 0.001$

${ }^{\dagger}$ Degrees of freedom $\left(\mathrm{F}_{\mathbf{1 . 4 1}, 29.67}\right)$ corrected using Greenhouse-Geisser estimates of sphericity $(\varepsilon=.71)$ as recommended by Girden (1992)

${ }^{\ddagger} \mathrm{r}=$ correlation coefficient. ${ }^{*}$ Unadjusted means used in calculating the means differences.

Table 2 Main Effects and Interaction Effects with corresponding Contrasts and Effect Sizes for all Measures 


\title{
Mindfulness Training and Employee Well-being
}

\begin{abstract}
Purpose - The aim of this paper was to assess the effects of Mindfulness Training (MT) on employee well-being. Mindfulness is the awareness of one's thoughts, emotions, sensations, actions, and surroundings in the present moment.

Methodology - We used pre-post training measures and a four week follow-up on a sample of 23 employees from a UK-based organization. The MT group $(n=12)$ received a weekly two-hour training over eight weeks whilst the control group $(n=11)$ received no training. Qualitative interviews $(n=36)$ were conducted with the MT group at 3 time points to further assess the subjective experiences of training participants.

Findings - Compared to the control group, the MT group significantly increased their mindfulness skills including observing and acting with awareness. Scores on well-being i.e. satisfaction with life, hope, and anxiety also improved and were generally maintained at follow-up. Some improvements were seen in the control group too but there was a larger difference in change scores in the MT group on most variables. Qualitative data show additional benefits of MT such as improved concentration at work and better interpersonal relationships. More practice at home led to greater benefits suggesting a dose-response relationship between the amount of practice and substantial benefits.

Research limitations/implications - Inviting participants to have a greater amount of practice between sessions may further increase the benefits of mindfulness. Future research should consider a longer follow-up period to further explore the sustainability of the training benefits.
\end{abstract}

Originality/value - Employing a mixed method approach, this study showed that MT is a viable psychological intervention for enhancing employee well-being.

Keywords: evaluation, mindfulness, training, controlled study

Paper type: Research 
Mindfulness Training and Employee Well-being

\section{Introduction}

Psychological research refers to mindfulness as an attribute of consciousness (Brown and Ryan, 2003) which can be conceptualised in a variety of ways. These include a dispositional personality trait innate for some individuals; a state of mind that can be cultivated through training and practice; a process; an outcome or a set of skills. Jon Kabat-Zinn, one of the most influential experts in the field conceptualised mindfulness as being "the awareness that emerges through paying attention on purpose, in the present moment, and non-judgementally to the unfolding of experience moment by moment" (Kabat-Zinn, 2003, p.145).

Research has found several key mechanisms explaining the benefits of mindfulness on a range of health, behavioural and cognitive outcomes (Brown et al., 2007). One of these mechanisms proposes that by cultivating a non-judging yet discerning observation of all the stimuli that enter their field of awareness moment by moment, individuals learn to let go of ruminations about the past and anxieties about the future and this enables them to respond more skilfully to challenging situations rather than adopting habitual unhelpful reactions (Shapiro et al., 2005).

In the last three decades, there has been consistent empirical evidence of the effectiveness of MT for a range of health conditions including chronic pain, heart disease, anxiety, depression, chronic diseases and eating disorders (Grossman et al., 2004; Grossman et al., 2010; Khoury, et al., 2013). However, the effectiveness of MT in the workplace has received comparatively little consideration in organizational scholarship, despite the potential benefits it can bring to employees (Dane and Brummel, 2013). Positive effects of MT interventions have been shown on resilience, well-being and stress reduction (e.g. Davidson et al., 2003; Shapiro et al., 2005; Brown and Ryan, 2007; Chiesa and Serretti, 2009; Virgili, 2013). However these outcomes have seldom been measured longitudinally in the workplace. The present study examines the effects of mindfulness training in increasing well-being among employees over time. Mindfulness can enhance well-being based on the assumption that mindfulness brings a more accurate view of reality. Having an accurate view of reality is considered in every theory of mental health as being the hallmark of psychological adjustment (Leary, 2004). By providing a clearer insight into reality of phenomena, as well as acceptance of one's individual states, mindfulness helps to reduce impulsive or defensive reactions to unsettling experiences and enhance well-being (Brown et al., 2007).

\section{Mindfulness skills}


Mindfulness skills have been construed in various ways and common constructs include observing, describing, acting with awareness, non-judging of inner experience, and nonreactivity to inner experience. A regular practice of watchful attention brings a more veridical perception of thoughts, emotions, and sensations (Grossman et al., 2004; Williams and Penman, 2011). This in turn enables individuals to act more wisely and skilfully, and less reactively. Research has shown that mindfulness skills are associated with a range of outcomes including reduced depression, anxiety and stress (Visted et al., 2014). However, there is a need to establish whether the MT actually leads to an increase in mindfulness skills. Not all studies report this evidence, yet it is one of the key mechanisms of change for individuals. In their meta-analysis, Visted et al., (2014) found that over half of studies had not shown any significant effects of MT on self-reported mindfulness skills. The inconsistency of these results was partly explained by the small sample size used in the studies reporting non-significant effects (37 out of 72). Overall, the number of participants (clinical and non-clinical populations) in this meta-analysis ranged from 10 to 320; the number of participants in non-clinical/working population ranged from 10 to 70 and comprised mostly university staff or health professionals. There were no significant differences in mean effect sizes for self-reported mindfulness when comparing clinical to non-clinical samples.

Mindfulness as a trait reflects the general tendency for individuals to abide in mindful states over time and across situations. On the other hand, mindfulness as a psychological state denotes an individual's ability to invoke a mindful mode of awareness at a given moment (Brown et al., 2007). Empirical studies have revealed a positive influence of mindfulness as a trait for example on job performance and work engagement (Dane and Brummel, 2013) and job satisfaction (Hulsheger et al., 2013). Whether mindfulness is a stable trait for some individuals or a momentary state for others, it is an inherently human quality that can be developed, so that individuals bring quality to the way they attend to thoughts, actions and emotional states. Research has shown that it can be developed with training (Shapiro and Izett, 2008). We therefore expect a significant increase in employees' mindfulness skills during MT relative to control group, with these effects maintained at follow-up (Hypothesis 1).

\section{Enhanced well-being}

Mindfulness has been shown to have the potential to increase positive aspects of well-being and to decrease negative ones (Brown et al., 2007; Jha et al., 2010; Keng, Smoski and Robins, 2011). In this study we operationalized well-being as positive evaluation of one's life 
satisfaction (Diener et al., 2002), with low levels of negative mood such as anxiety (Huppert and Whittington, 2003) and positive mental capital such as hope (Luthans et al., 2007).

\section{Satisfaction with life}

Satisfaction with life is said to be relatively stable across time, but moods and emotions are changing and momentary (Fullager and Holloway, 2009). Thus, we hypothesized that MT may improve Satisfaction with Life (Hypothesis 2) by enabling individuals to improve cognitive emotional control (Jha et al., 2010). Recent research (Lutz et al., 2014) suggests that more mindful individuals are able to attenuate emotional arousal when negative stimuli are presented to them. The MT may enable individuals to re-evaluate more positively their life as they learn to appreciate more the present moment, and also to de-centre from difficult thoughts. De-centering is defined as the ability to observe one's thoughts and feelings as temporary and as objective events in the mind as opposed to reflections of the self that are necessarily true (Safran and Segal, 1990; Fresco et al., 2007). An individual engaged in decentering sees the reality of what they experience as not immutable but changeable. One may say, "I am thinking that I feel anxious right now" instead of "I am anxious". De-centering has been suggested as one of the mechanisms by which mindfulness can improve well-being (Shapiro et al., 2006).

\section{Decreased anxiety}

Anxiety can be conceptualised as a negative aspect of well-being (Huppert and Wittinghton, 2003). It relates to attentional biases towards threats, repetitive negative thinking, physiological hyperarousal, avoidance behaviours and deficit in emotion regulation (Vollestad et al., 2012). In their systematic review, Vollestad et al. found that MT interventions were effective in reducing anxiety symptoms. The MT approach to reducing anxiety differs from conventional approaches, such as cognitive behavioural therapy (CBT). CBT seeks to help individuals to analyse and change their maladaptive existing patterns of thinking, emotional reactions and behaviours by trying out new approaches (Sheldon, 2011). On the other hand, the MT approach does not emphasise modification of the content of cognitions. Instead the aim is a shift in how individuals relate to their anxiety and become less identified with their thoughts (Vollestad et al., 2012). Instead of avoiding or withdrawing from feelings of anxiety, or distressing thoughts, MT invites individuals to fully attend to them, in an effort to acknowledge that these thoughts and feelings are not facts but the product of their subjective perceptions. Anxiety is therefore expected to decrease as a result of MT (Hypothesis 3) as individuals develop a greater ability to disentangle their thoughts from reality. 
Increased hope

Another construct which is closely related to individual well-being because it is part of positive 'psychological capital' is hope (Luthans et al., 2007). Hope enables individuals to not only have willpower to pursue goals that are relevant for them but also facilitate the generation of multiple pathways to achieve these goals (Snyder, 2002; Youssef and Luthans, 2007). Since MT helps individuals to view a situation through a different perspective or "reperceive" it, this enables them to consider alternative solutions to a problem (Shapiro et al., 2006), thereby deploying greater psychological flexibility and hope. We therefore posited that participants' hope in particular may increase after training (Hypothesis 4).

\section{Maintenance of MT impact over time}

Despite the popularity of mindfulness interventions, much of the relevant research does not include follow-up measures. The effects of MT were assessed both qualitatively and quantitatively, at 3 time points i.e. prior to the training, just after training and four weeks after the training. Strictly speaking our study design cannot be considered truly longitudinal due to the short time (12 weeks) between Time 1 and Time 3. However, it does enable a test of the short-term stability of MT effects and also an examination of whether participants in MT maintain their self-driven practice of mindfulness in the weeks following the MT. We were limited to a four-week follow-up by the need to deliver follow-up sessions reasonably soon after the MT training, and we did not want these to contaminate our findings. Also, the researchers were available only for a fixed period of time to collect the data.

We expected maintenance of MT impact after training rather than further substantial improvements over a four-week follow-up period. Virgili's (2013) meta-analysis of six intervention studies $(n=193)$ found that the effects of MT on reducing psychological distress in working adults were maintained at a median follow-up of 5 weeks (the range was 4 to 20 weeks). In the present study, participants were encouraged to practise mindfulness after the eight-week MT course and the expectation was that they would do so to maintain any benefits of the MT.

\section{Hypotheses and Research Questions}

Based upon the theory and research reviewed above, we propose that: the mindfulness training will (a) lead to significant increases in mindfulness skills and well-being in the trainees over the duration of the training course compared with a control group who do not 
undertake the training and (b) this advantage will be maintained over the following four weeks. Specifically, we tested this general proposition with the following variables:

- Mindfulness skills (Hypotheses 1a and 1b)

- Satisfaction with life (Hypotheses $2 \mathrm{a}$ and $2 \mathrm{~b}$ )

- Anxiety (Hypotheses 3a and 3b)

- Hope (Hypotheses 4a and 4b)

In addition to our quantitative hypotheses, we assessed the subjective experiences of participants before and after training and at follow-up through qualitative telephone interviews. The aim was to identify learning mechanisms and additional benefits of mindfulness practice not captured by the use of quantitative measures. Current psychometric scales are said to be weak in capturing certain domains such as enhancement of interpersonal relationships (Sauer et al., 2013) therefore it was expected that qualitative interviews may help to identify additional MT effects. We pose two research questions:

RQ1: What additional benefits of MT, if any, do participants identify, and are these maintained after the end of the MT?

RQ2: What are the dynamics of the process of mindfulness development during and after the MT?

\section{Value of the present study}

We believe that the present study makes an important contribution to existing evidence in several ways. First, it adds to the body of research on mindfulness in the workplace, assessing the importance of such interventions for employee well-being and for organizations as subjective affective well-being is associated with job performance (Daniels and Harris, 2000). Second, it assesses MT results over time allowing an understanding of how and when learning takes place as well as the amount of practice and change effects observed. Third, it includes a control group of people similar to those undertaking the MT. Fourth, participants included low health risk employees (as per the initial screening application process for the training) providing evidence about whether MT can be a preventive intervention for such a population and not only relevant for those suffering from a health condition (Hotzel et al., 2011). Lastly, a mixed-method design using qualitative interviews in addition to a quantitative data is rarely reported in the literature and yet the value of mixed methods is that the triangulation of data can provide a richer view of the benefits of training than one method alone. 
Method

Study design

A mixed-method (quantitative and qualitative) approach informed the research. A quasiexperimental, pre/post/follow-up design with comparison group was used to test our hypotheses. The addition of a comparison group in an MT study adds rigour to the study design, consequently enhancing decisiveness in the interpretation of causal inferences (Jacobs and Nagel, 2003). A questionnaire was administered to both the training group and the control group three times (baseline, i.e. just before the start of the training T1; immediately after training T2; at four-week follow-up, T3). The independent variables were i) the treatment with two levels: the MT training and the control group, and ii) the time with three levels: T1, T2, T3. The dependent variables were the change scores on outcomes of selfreported mindfulness and well-being variables.

Qualitative semi-structured interviews were conducted with the MT participants at T1, T2, and T3. They focused on exploring trainees' perceived benefits and challenges during and after the MT. An interview question guide was developed for each time-point based on the literature review and topics relevant to mindfulness practice. The interviews were conducted over the phone, and lasted 45 minutes on average. They were recorded with participants' permission and transcribed.

\section{Sample and procedure}

The sample originally comprised 24 individuals: 12 trainees and 12 controls but the final sample included 11 controls (as one participant did not return all questionnaires). Trainees were individuals who volunteered to attend the eight-week mindfulness training programme after a presentation on mindfulness benefits given at a lunch time seminar and attended by 90 staff within a medium-sized research based public sector organization. Control group participants were a group matched by grade and department. Trainees comprised 6 males and 6 females while the control group had 7 males and 5 females. Employee grade across the sample ranged from junior to senior grades including 2 with managerial responsibilities. Participants included business managers, engineers, ergonomists, project managers, social scientists and system administrators across 10 different departments. Non-parametric analyses revealed no significant differences between the trainees and controls in terms of gender, employee grade, department and job type. A total of 36 telephone interviews were successfully conducted at three time points with the 12 trainees. The study received ethical 
approval from the University of Sheffield (United Kingdom) where three of the authors conducting the MT course evaluation were based. The first author delivered the training.

\section{The Mindfulness Training}

The MT content was based upon the well-established Mindfulness Based Stress Reduction (MBSR) program. MBSR is a group-based structured intervention consisting of an eightweek programme of two-hour weekly sessions. Formal mindfulness meditation practice 'homework' in between sessions was of shorter duration (20-30 minutes) than recommended (45 minutes) for six days/week due to participants' time availability. Informal practice also formed an important part of the training. The format of the MT reported in this study did not include the one day retreat recommended in the MBSR programme due to resource availability. Other authors (e.g. Shapiro et al., 2005; Klatt et al., 2009; Brown et al., 2009) have also used this shortened format. Previous research found that the effectiveness of MT in reducing psychological distress is not a function of the duration of the intervention, whether measured as number of weeks or quantity of class contact time (Virgili, 2013). The MT was delivered on-site during the lunch time period. It was free of charge for the participants and their attendance time was recorded as working time.

The MT included a mix of didactic presentations, group discussions and formal mindfulness meditation practices (body scan, mindful movements, three minute breathing space, walking, and befriending meditations). Presentations were given on topics such as the physiology of stress and applying mindfulness skills to communication situations. The MT aimed to assist participants in learning new ways to handle thoughts, physical sensations, emotions, moods, and social interactions so as to respond to challenging events more skilfully. The content of the course was highly experiential. Participants were provided with a book (Mindfulness: A Practical Guide to Finding Peace in a Frantic World by Williams and Penman, 2011), and recorded instructions on a CD for mindfulness meditation exercises between sessions. A participant handbook was also used by participants for reflecting on and writing their daily experiences of their formal and informal mindfulness practice. The trainer was at the time a member of staff from the same organization as the participants, with many years of meditation practice, and trained in delivering the eight-week mindfulness course. The trainer was supervised by an external mindfulness trainer during the MT.

\section{Measures}

The assessment of the MT included validated and widely used scales. 
Mindfulness skills

The Kentucky Inventory of Mindfulness Skills (KIMS; Baer et al., 2004). This is a 39-item questionnaire that measures four components of mindfulness: Observing (12 items): being able to notice one's experience (Cronbach's alpha was $.89, .92 .92$ at the three time points respectively. Describing ( 8 items): articulating an experience (Cronbach's alpha was $.88, .85$ .93). Acting with awareness (10 items): being fully in the present moment (Cronbach's alpha was $.85, .87 .84$ respectively). Accepting without judgment (9 items): being non-judgmental, non-evaluating self-experience (Cronbach's alpha was. 86, .87, .86 for T1, T2 and T3 respectively). A 5-point scale was used with responses ranging from 1 (never or very rarely true) to 5 (very often or always true) yielding a total sum score ranging from 12 to $60 ; 8$ to 40 ; 10 to 50; and 9 to 45 for each subscale respectively.

\section{Well-being}

\section{Satisfaction with Life}

The Satisfaction With Life Scale (SWLS; Diener et al., 1985) is a 5-item scale designed to measure global cognitive judgments of one's life satisfaction such as "If I could live my life again, I would change almost nothing”. Participants indicate how much they agree or disagree with each item using a 7-point scale that ranges from 7 (strongly agree) to 1 (strongly disagree) yielding a total of sum score that ranges from 5 to 35 . Cronbach's alpha was .92, .91, .93 for T1, T2 and T3 respectively.

\section{Anxiety}

The Beck Anxiety Inventory (BAI; Beck et al, 1988) is a 21-item list of common symptoms of anxiety, with two factors (somatic symptoms and subjective anxiety/panic symptoms). Respondents indicated how much they had been bothered by the listed symptoms during the past month. Examples included "unsteady; "terrified or afraid"; "feeling hot"; "hands trembling”. Participants were asked to rate their experience of these symptoms on a 4-point scale from 0 (not at all) to 3 (severely - it bothered me a lot) yielding a total of sum score ranging from 0 to 63 . Cronbach's alpha was .77, .79, .80 at T1, T2, and T3 respectively.

\section{Hope}

The State Hope Scale (Snyder et al., 1996) contains 6 items that measure an individual's current opinions about their ability to consider alternative solutions to a problem (Pathway) and their persistence at it (Agency). Each question had a 1-8 response scale ranging from 1 (definitely false) to 8 (definitely true) so total scores could range from 6 to 48 . Example questions included: "If I should find myself in a jam, I could think of many ways to get out of 
I," and "At the present time, I am energetically pursuing my goals". Cronbach's alpha was $.85, .85, .89$ for the three time points respectively.

\title{
Benefits from the Mindfulness Training
}

At the end of the training, participants were invited to rate their overall level of satisfaction with the training and how much they could apply it to work situations. The questions were "Overall how would you rate the usefulness of this course for you?" assessed on a 5-point scale from 5 (very useful) to 1 (not very useful) and "To what extent could you apply what you learnt during the course to work situations?" ranging from 5 (very frequently) to 1 (very rarely). At T3, participants were also asked the extent to which they the benefit(s) mentioned at T2 had changed in the subsequent four weeks (assessed as "remained the same", "increased" or "decreased").

The qualitative interviews focused on exploring perceived benefits and challenges during the MT. At T1, the interview questions focussed upon the participants current workplace stressors, and how committed they were to engaging in the course. At T2, participants were asked if the MT had fulfilled their expectations and about any further benefits; for example; 'What other benefits, in relation to your work or home life, have you experienced after going through this training programme?' Participants were also asked to discuss the major challenges they experienced during the training. Course-specific questions were also asked at T2 about the quality of the training, the most useful elements of it and challenges for application in everyday life. Finally in T3, participants were asked if the benefits they reported at T2 had were still evident, and whether they had experienced any new benefits since the end of the course, and what factors had either facilitated or hindered their ability to continue with mindfulness practices since the end of the course.

\begin{abstract}
Analysis
A series of $2 \times 3$ mixed ANOVAs was performed to test our hypotheses. Tests of normality of distribution and homogeneity of variance were conducted. Condition (MT vs Control) was the between-subjects factor, and Time (Three time points: T1, T2, T3) was the within-subjects factor.
\end{abstract}

Interaction contrasts were performed for specific paired comparison (i.e. T2 vs T1; T3 vs T2) to identify differences between time points and condition. T2 vs T1 contrast indicated change in scores due to training whilst T3 vs T2 contrast indicated the maintenance of effect over time. Effect sizes represented by correlation coefficients and differences in means scores 
were calculated. To calculate the mean-score differences for the MT group we took into account the increase in scores in the control group. This provided the relative increase in mean scores for the MT group when compared with the control group. Effects sizes were interpreted following Cohen's (1988) recommendations.

The qualitative interviews focused on exploring perceived benefits and challenges during the MT. Qualitative content analysis (Patton, 1990) was used in order to identify patterns in the data and extract common and salient themes. Two researchers independently read all transcripts and conducted a content analysis to extract common themes. This was an iterative process where codes were developed and then discussed before arriving at an agreement. Higher order categories were derived from the coding and split into further subcategories. Qualitative content analysis was used because we were interested in the frequency/weight given by the number of statements as well as the content of the narrative statements.

\section{Results}

Descriptive statistics are shown in table 1. All means and standard deviations for each scale and subscale at each time point were calculated.

Insert table 1 about here

\section{Mindfulness Training Effects}

Table 2 shows the ANOVA main effects and condition by time interaction effects for all measures. It also shows the interaction contrasts with their corresponding effect size calculations. Some improvements can be seen in the control group as well as in the MT group. However, our interaction contrasts analysis performed on each variable revealed a significant difference between conditions (control or training) suggesting improvements due to training. Larger improvements were observed in the MT group on most variables as explained below.

Insert table 2 about here

\section{Mindfulness Skills}


Overall the results provide substantial support for Hypothesis 1 which stated that MT participants will increase their mindfulness skills and maintain improvements at follow-up. At least two out of four mindfulness skills have significantly improved.

\section{Observing}

The analyses revealed a significant main effect of Time, $F(2,42)=16.23, p<.01$, and a significant Condition $\mathrm{x}$ Time interaction, $F(2,42)=4.04, p<.05$ for the Observing facet indicating MT and Control Group differ over time. The interaction contrast between T2-T1 was significant $F(1,21)=8.90, p<.01$, with a large effect size $(r=.55)$ suggesting improvements after training. The difference in means for T2-T1 shows that the Observing scores mean in the MT group increased by 6.4 . This was calculated after taking into account the increase in Observing score in the control group.

The T3-T2 interaction contrast for Observing scores was not statistically significant, suggesting no change in improvement scores seen after training, (neither further improvement nor decrease in benefits), hence improvements were maintained over the follow-up period. This finding suggests a maintenance effect rather than an improvement effect.

\section{Describing}

There was a significant main effect of Time, $F(2,42)=11.54, p<.001$, and significant Condition $\mathrm{x}$ Time interaction, $F(2,42)=6.18, p<.01$ for the Describing facet. Although the interaction is statistically significant, the T2-T1 and the T3-T2 interaction contrasts are not statistically significant. This appears to be because there are small improvements between T1 and T2 and between T2 and T3. These small improvements are not large enough to be important on their own, but added up over the whole study period T1-T3 the differences between the two groups become significant. This suggests that improvements although of a small magnitude were being maintained over time.

\section{Acting with awareness}

There was a significant main effect of Time, $F(2,42)=11.48, p<.001$, and the Condition $\mathrm{x}$ Time interaction was significant, $F(2,42)=14.74, p<.001$ for Acting with Awareness scores. Interaction contrast T2-T1 was significant $F(1,21)=21.30, p<.001$ with a large effect size $(r=.71)$ indicating an increase in Acting with Awareness scores after training. The effect size in means for T2-T1show that the relative increase in the mean Acting with Awareness score for the MT group was 7.6.

The T3-T2 interaction contrast for Acting with Awareness scores was not statistically significant, suggesting no change in improvement scores seen after training, (neither further 
improvement nor decrease in benefits), hence similar levels of improvements were maintained over the follow-up period.

\section{Accepting without judgement}

There was a significant main effect of Time, $F(2,42)=17.18, p<.001$, and the Condition $\mathrm{x}$ Time interaction was significant, $F(2,42)=5.13, p<.05$ for Accepting without judgement facet. Although the interaction is statistically significant, the T2-T1 and the T3-T2 interaction contrasts are not statistically significant. This is due to small improvements between $\mathrm{T} 1$ and $\mathrm{T} 2$ and between $\mathrm{T} 2$ and $\mathrm{T} 3$. These small increases are not large enough to be important on their own, but added up over the whole study period T1-T3 the differences between the two groups become significant. This suggests that improvements although of a small magnitude were being maintained over time.

In summary, hypothesis 1a was partly supported in that two of the four mindfulness skills significantly improved between the start and end of the MT (Observing and Acting with Awareness) whilst the two others (Describing and Accepting without Judgement) did not. Overall, there was support for hypothesis $1 \mathrm{~b}$, with no significant differences between the training and control groups in changes in scores over four weeks after the end of training.

\section{Well-being}

\section{Satisfaction with Life}

There was a significant main effect of time, $F(2,42)=19.98, p<.001$ and the Condition $\mathrm{x}$ Time interaction was significant, $F(2,42)=4.17, p<.05$ for Satisfaction with Life.

The interaction contrast T2-T1 was significant $F(1,21)=5.69, p<.05$ with a medium effect size $(r=.46)$ indicating an increase in Satisfaction with Life scores after training. The relative increase in the mean Satisfaction with Life scores for the MT group was 3.1.

The T3-T2 contrast was not statistically significant, suggesting no change in improvement scores seen after training, (neither further improvement nor decrease in benefits). Hypothesis $2 \mathrm{a}$ and $2 \mathrm{~b}$ were fully supported with a positive change during training and maintenance of effects afterwards.

\section{Anxiety}

There was a significant main effect of time, $F(2,42)=7.49, p<0.01$ but the Condition $\mathrm{x}$ Time interaction was not significant, $F(2,42)=1.56$, n.s. The T2-T1 contrast $F(1,21)=4.48, p$ $<.05$ was significant with a medium effect size $(r=.42)$ showing a significant improvement i.e. a reduction in anxiety scores for the MT group. The reduction in the mean Anxiety Score for the MT group relative to the control group was 4.7 . 
The T3-T2 interaction contrast was not significant, suggesting that the reduction in anxiety was maintained. Although there was an increase in Anxiety scores of 2.3 in the MT group between Time 2 and Time 3, this was not statistically significant. Therefore hypotheses $3 \mathrm{a}$ and $3 \mathrm{~b}$ were supported in that Anxiety scores of the MT participants significantly decreased during training relative to the control group and the changes between T2 and T3 for the two groups did not differ significantly.

\section{Hope}

Analyses revealed a significant main effect of Time, $F(2,42)=9.76, p<.05$, and the Condition $\mathrm{x}$ Time interaction was significant, $F(2,42)=5.46, p<.01$ for Hope. The interaction contrast between T2-T1 was significant $F(1,21)=5.52, p<.05$ with a medium effect size $(r=.46)$ indicating an increase in Hope after training. The relative increase in the mean Hope scores for the MT group was 1. The T3-T2 contrast was not statistically significant, suggesting similar levels of improvements in Hope were maintained over the follow-up period. Hypotheses $4 \mathrm{a}$ and $4 \mathrm{~b}$ were therefore fully supported with a positive change after training and then maintenance of effects.

\section{Rating of usefulness of training and practice time}

Trainees rated the course overall as being very useful (10 out of 12 respondents). When asked the extent to which they could apply what they had learnt to work situations, 9 out of 12 respondents stated their learning was frequently or very frequently applied; whilst 3 applied their learning occasionally to work situations.

At the four-week follow-up, five participants reported a further increase in benefits. Five reported having the same benefits as after training and two said they experienced decreased benefits.

\section{Practice time}

Among trainees, the total average mindfulness practice time per week was higher at $\mathrm{T} 2$ (Mean= 134 minutes, $\mathrm{SD}=112)$ than at $\mathrm{T} 3(\mathrm{M}=88.4$ minutes, $\mathrm{SD}=78)$. A related-samples Wilcoxon signed rank test revealed that this was a significant difference, $p<.05$. However, those who qualitatively reported a continued increase in benefits at T3 were practising for a longer duration at $\mathrm{T} 3(\mathrm{M}=155 ; \mathrm{SD}=76)$ as compared to those reporting a maintenance of benefits $(\mathrm{M}=38 ; \mathrm{SD}=15)$ or a decrease $(\mathrm{M}=48 ; \mathrm{SD}=67)$. An independent-sample Kruskal-Wallis test revealed that there was a significant difference $(p<.05)$ between the 
three groups. Further pairwise comparisons revealed that the significant difference was between those who reported an increase $v s$. maintenance in benefits.

\section{Qualitative findings from interviews}

The interview data provided additional insights about the benefits of MT experienced by participants, thus addressing our Research Question 1. The well-being theme partly overlaps with the quantitative data reported above, but the concentration and interpersonal skills themes go well beyond the quantitative data.

\section{Well-being}

The majority of participants reported experiencing less stress as well as increased life satisfaction and more perspective in their lives in terms of values and goals as benefits of MT. 'I've learnt tools to help me cope with the stress and put things into perspective really. They don't seem such big issues now; the stressful aspects of my work and when I do get stressed or get in confrontational situations I think I'm able to cope significantly better now'. They also felt more compassionate and kinder towards themselves whenever they felt inadequate in handling a situation. Instead of identifying themselves as failures, they were accepting their limitations. Another insight that trainees gained was a clarification of their values. Shapiro and colleagues (2006) argue that in re-perceiving and identifying one's values, the individual is better able consciously to choose values that are true to one's self, rather than merely following values that are espoused by society. In clarifying their values and showing more self-compassion, this had an impact on participants' well-being. For example, some were more willing to spend time with their families and not worry about work all the time. "I've got a pretty happy home life but I wasn't really fulfilled at work to be honest and this course has helped me to improve that significantly because at work I'm enjoying things quite a bit more and less anxious and don't worry so much. I'm a far happier worker". Such findings resonate with the large amount of mindfulness literature on the positive effects of mindfulness training on participant well-being (e.g. Brown and Ryan, 2003).

\section{Concentration at work}

By engaging in mindfulness meditation, participants were encouraged to notice whenever their mind wandered and guide their thoughts back to their object of focus. Most training participants reported improvements in their ability to concentrate at work. "I can maintain my concentration better than before... I've got more peace of mind". In addition, some claimed 
that they were better able to focus at work because they were able to sleep better. Previous studies have demonstrated that low quality sleep can affect one's cognitive functioning and ability to concentrate (Ulfberg et al., 1996). These findings are consistent with research showing that mindfulness is able to improve individuals' quality of sleep (e.g. Carlson and Garland, 2005), thereby improving the ability to focus at work. Along with being able to concentrate on one task at a time, participants reported being more organised. Some said that they wrote down to-do lists to keep track of what needed to be done. In becoming more mindful this way, they would stop worrying about those items and solely focus on the task at hand, further bolstering their attempts to concentrate at work. "At work, I can plan things better now, so I can organise what I'm going to do instead of reacting. I can just take time to be proactive and itemise what I'm doing and prioritise what I'm doing, instead of just panicking”. The findings are consistent with studies reporting benefits in terms of improved sustained attention and executive functioning following mindfulness training (Chiesa et al., 2011; van den Hurk et al., 2010).

\section{Interpersonal skills}

Participants' increased mindfulness allowed them to regulate their reactions to other people more effectively, thus improving interpersonal relationships, especially at work. Trainees reported an increase in empathy, a finding that is similar to that of Cohen-Katz et al., (2005). Through extending compassion towards others in the befriending meditation, participants were encouraged to appreciate that other people are in fairly similar situations in their work environment (i.e., they experience similar work pressures and want to succeed in the job). Furthermore, in being able to disrupt habitual unhelpful responses to situations, some reported that they stopped reacting defensively during interactions with others. They were also able to improve the way they related with others. 'I don't react so much to certain situations, you know potential arguments or potential disagreements or whatever.'

\section{Enablers and barriers to mindfulness practice}

The data reported in this sub-section address Research Question 2, concerning the dynamics of development during and after the MT. With respect to the course as a whole, all participants felt it was an enjoyable experience, with some wishing that it would have carried on beyond the eight weeks. Most perceived the trainer as highly experienced. Some of the most useful aspects of the course were the mindfulness meditation practices that trainees learnt, especially the three-minute breathing space meditation, and the group discussions. ' $I$ use [the three minute breathing space meditation] ... quite often at work, it's really, really 
useful, and it just helps me refocus and calm down, re-energise and refresh and then just carry on and do things a lot better.'

Experiencing the benefits of mindfulness was a positive reinforcement, which spurred participants on to continue with their practice. Others commented that some practices were intrinsically rewarding because they simply enjoyed doing that particular exercise. It was also said that certain situations triggered them to practice mindfulness. For instance, some spoke about receiving facilitation or encouragement from colleagues or relatives to maintain their practices. A few were able to ask their family members to give them the time and space to practice without interruptions. Interest in mindfulness was further sustained by reading books on the topic.

Some of the main factors hindering continued mindfulness practice were the difficulty in finding the time or the self-effort to do the daily formal exercises, with nine participants reporting this. These issues were also reported in other studies (Cohen-Katz et al., 2005). Participants were encouraged to attend all sessions where possible and required to inform the trainer in advance of their absence. Two missed a session due to illness and a few others missed a session due to work commitments. Participants were asked to catch up with the upcoming weekly exercises as described in their handbook whenever they could not attend a session. The MT provided during lunch time hours was a suitable time for most especially those who had a long commute but it did not suit a few who wanted to enjoy their lunch break. The lack of a dedicated place at work for formal mindfulness exercises was reported as a hindering factor to continued practice.

\section{Discussion}

This study sought to evaluate the effects of mindfulness training on employees' mindfulness skills and well-being. Overall our study hypotheses predicting improvements in mindfulness skills and well-being after a mindfulness-based training were supported. This study found significant increases in self-reported mindfulness skills that are attributable to the mindfulness training. This is a promising finding as not all studies report significant results (Visted et al., 2014), making it difficult to know whether the mindfulness training or other factors had impacted outcomes. In common with many other mindfulness studies, the present study employed a small sample and therefore the differential increase between the training and control groups had to be quite large to reach significance. This provides evidence that mindfulness skills can be developed through training and can help those individuals with low dispositional mindfulness. However, we found that not all facets of mindfulness skills 
developed systematically. Some developed after training and others over time suggesting perhaps that not only training but a longer period of mindfulness practice is needed for skills to develop.

\section{Enhancement of well-being through mindfulness}

Many studies have shown that mindfulness skills are associated with employee well-being (Brown et al., 2009; Brown and Ryan, 2003; Shapiro et al., 2005). Our findings confirm previous research. Training participants reported enhanced well-being through greater satisfaction with life, hope and decreased anxiety. Interestingly, the qualitative interviews confirmed the enhancement of well-being after training. In addition, participants experienced a greater ability to concentrate at work, feeling less stressed and having better interpersonal relationships. The majority of training participants reported an increased life satisfaction and having gained more perspective in their lives. The concept of being satisfied with what one has relative to others is at the core of life satisfaction. Rosenberg (2004) proposes that savouring the present moment may make mindfulness practitioners prize intrinsic values such as relationships and personal development, over extrinsic wealth or material possessions.

Training participants also reported a greater sense of hope as a result of training. This finding is consistent with the results reported by Sears and Kraus (2009). Mindfulness helps individuals to view a situation from a different perspective and this enables them to consider alternative solutions (Shapiro et al., 2006). Hope might have increased through this mechanism. During interviews, participants reported being able to stop their habitual responses to situations and pause to re-evaluate their situation. By disrupting their autopilot, they were then better able to think of alternative ways of handling an issue.

Although statistical significance tests supported our hypotheses predicting reduced anxiety after training, there were signs that it was rising again during the follow-up, although not significantly. This is contrary to previous research which has found that reductions in anxiety attributable to mindfulness training were sustained at follow-up (e.g. Davidson et al., 2003; Grossman et al., 2007). One explanation for anxiety levels rising again at follow-up could be that participants were becoming more aware of anxiety symptoms as a result of training. During the training, exercises such as the body scan encouraged participants to explore somatic sensations, to observe what is occurring within one's body without attempting to change it. As participants were not asked to suppress or change unpleasant sensations but instead to notice and accept them, they may have reported experiencing the somatic symptoms of anxiety because they noticed them more. Becoming more aware of own internal states may also affect the reporting of symptoms more accurately. It is reassuring 
however that interview findings revealed that more than half of participants still enjoyed relatively low levels of stress at follow-up, and some spoke of less panic.

It is worth noticing that participants' levels of anxiety were relatively low at baseline making it perhaps difficult to reduce further. Normative data suggest that the Beck Anxiety Inventory scores between 0-9 reflect minimal or normal anxiety; 10-18 mild; 19-29 moderate to severe; and 30-63 severe (Wilson et al., 2004). Results for the MT group were mild at baseline (14.2), normal or minimal after training (6.9) and still close to the normal range at follow-up (9.6) despite a slight increase.

\section{Dose-response relationship between practice and benefits}

Our findings warrant a discussion of the amount of mindfulness meditation practice that is necessary to produce benefits. One important finding is that the amount of practice time was associated with sustained benefits of mindfulness suggesting that a dose-response relationship may be at play in the observed positive changes. The longer the amount of practice was, the greater the benefits reported. The training itself and the amount of daily mindfulness practice suggested in the present study was lower than that of a standard MBSR programme. Despite the reduced practice time, most of our hypotheses stating a positive change during training were supported. As commented by Kabat-Zinn et al., (1987) there are conflicting results on the amount of practice required with some studies indicating that occasional practice is as effective in symptom reduction as regular practice and that it is perhaps whether one is practicing at all that makes the difference in outcomes. Further, the quality of mindfulness practice may be more important than the frequency (Del Re et al., 2013) and the extent to which it has been integrated into the individual's everyday life. This in turn may partly depend on the quality of course materials and the trainer's own mindfulness skills. In this particular study, the course and the trainer were highly rated. However, a few participants reported struggling to find time for their personal practice and this may have limited the benefits of MT that they experienced. There was evidence at follow-up that a few participants reported feeling stressed as well as having reduced their amount of mindfulness practice. Whilst mindfulness training at the workplace may be shorter to accommodate workers' time constraints, future training content needs to reiterate to participants the importance of sufficient daily practice outside of training.

\section{Study limitations and implications}

There are several limitations that need to be taken into account before drawing definite conclusions from the results. One limitation relates to the use of a quasi-experimental design 
where participants were not randomised. This increased the likelihood that the treatment and control groups were not comparable in terms of the factors which may affect the outcomes. This choice was due to the small number of volunteers available at the time for attending the training or be part of a wait-list. However, the results largely corroborate previous research and the qualitative findings reflected improvements due to the training. Another limitation is the small sample size which may have led the study to be insufficiently powered and made it more difficult to detect a difference between groups. On the other hand, having found significant results using such small sample size gives credence to the mindfulness training effects.

The follow-up period may have been of too short in duration to measure the true maintenance effects of the changes due to training and therefore future studies need to consider a longer time period to draw any firm conclusions on the maintenance effects. Since follow-up training sessions have been found to be beneficial in meta-analytic studies, one implication of this study is to recommend the integration of follow-up sessions after the formal eight-week training to benefit individuals who show low self-effort in maintaining their mindfulness practice.

Another implication of our findings is the consideration of organizational contexts in which mindfulness skills can be best developed. Social learning gained from group discussions and exchange with others may have facilitated learning and increased motivation further. Participant accounts suggest the need for continued practice within the workplace to maintain benefits. For this, organizations need to have arrangements in place for facilitating periods of practice and learning such as allocating time for formal practice. Although mindfulness can be practised anywhere and at any time, some participants prefer to have a dedicated room for their formal practice whether for lying down doing a body scan or a sitting meditation without being disturbed. Some organizations that recognise the evidencebased benefits of mindfulness have already provided such facilities for their employees.

Future research should extend the assessment of MT effects to work outcomes variables such as performance, work engagement or job satisfaction to convince employers of the specific value of such interventions in the workplace. Objective and behavioural outcome measures of psychological functioning should also be used rather than relying on self-report measures alone (Virgili, 2013).

To protect anonymity because of the small group size, we did not ask demographic questions in great details. However the profile of our sample was mainly white, educated, but equally distributed in term of gender. The results may therefore apply to groups with these 
socio-demographic characteristics. Further research should reach other socio-demographic groups in the workplace (e.g. operational staff, minorities) and assess the most effective ways of training these various groups on mindfulness. The use of blended learning (on the job learning, classroom based type, e-learning, coaching) is currently the leading method of imparting knowledge and skills. Therefore using a range of media such as e-devices, informal gatherings as well as classroom-based training may suit the learning styles and needs of various groups and especially those under time or location constraints.

If mindfulness helps individuals to notice signs of stress or anxiety, then it can help them deal with these issues earlier before they intensify and degrade their health. MT is already an approach that is provided to clinical populations but it may also be a powerful and relatively cost effective way to increase the mental well-being for the general population and individuals with low health risks or moderate mental health issues, which represent the majority of individuals (Huppert, 2004).

\section{Conclusion}

Mindfulness training represents a novel way of enhancing employee well-being. Overall, the findings of this study are encouraging and provide support for the use of MT as a shorter version of MBSR training program in a work setting. Future research will need to determine the optimal intervention characteristics (e.g. programme duration and frequency of in-class hours; amount of practice) for use within organizations. This study contributes to the increasing body of evidence on the effectiveness of mindfulness training for employees who wish to enhance their well-being and concentration at work.

\section{References}

Baer, R. A., Smith, G. T., and Allen, K. B. (2004), “Assessment of mindfulness by selfreport: The Kentucky Inventory of Mindfulness Skills”, Assessment, Vol. 11, pp. 191206.

Beck, A. T., Epstein, N., Brown, G., and Steer, A. (1988), “An inventory for measuring clinical anxiety: Psychometric properties", Journal of Consulting and Clinical Psychology, Vol. 56, pp. 893-897.

Brown, K., and Ryan, R. M. (2003), "The benefits of being present: Mindfulness and its role in psychological well-being", Journal of Personality and Social Psychology, Vol.84, No. 4 , pp. 822-848. 
Brown, K., Ryan, R., and Creswell, J. (2007), "Mindfulness: Theoretical foundations and evidence for its salutary effects", Psychological Inquiry, Vol. 18, pp. 211-237.

Brown, K., Kasser, T., Ryan, R. M., Linley, A., and Orzech, K. (2009), "When what one has is enough: Mindfulness, financial desire discrepancy, and subjective well-being", Journal of Research in Personality, Vol. 43, pp. 727-736

Carlson, L. E., and Garland, S. N. (2005), "Impact of mindfulness-based stress reduction (MBSR) on sleep, mood, stress and fatigue symptoms in cancer outpatients", International Journal of Behavioral Medicine, Vol. 12, pp. 278-285.

Chiesa, A. and Seretti, A. (2009). "Mindfulness based stress reduction for stress management in healthy people: A review and meta-analysis", The Journal of Alternative and Complementary Medicine, Vol. 15, No. 5, pp. 593-600.

Chiesa, A., Calati, R., and Serretti, A. (2011), "Does mindfulness training improve cognitive abilities? A systematic review of neuropsychological findings", Clinical Psychology Review, Vol. 31, pp. 449-464.

Cohen, J. (1988), Statistical Power Analysis for the Behavioral Sciences, Lawrence Erlbaum Associates.

Cohen-Katz, J., Wiley, S., Capuano, T., Baker, D. M., Deitrick, L., \& Shapiro, S. (2005). "The effects of mindfulness-based stress reduction on nurse stress and burnout: A qualitative and quantitative study, part III", Holistic Nursing Practice, Vol. 19, pp. 78-86.

Dane, E. and Brummel, B.J. (2013), "Examining workplace mindfulness and its relations to job performance and turnover intention”, Human Relations, Vol. 67, No. 1, pp.105128.

Daniels, K., and Harris, C. (2000), "Work, well-being and performance”, Occupational Medicine, Vol. 50, pp. 304-309.

Davidson, R. J., Kabat-Zinn, J., Schumacher, J., Rosenkranz, M., Muller, D., Santorelli, S. F., Urbanowski, F., Harrington, A., Bonus, K., and Sheridan, J. F. (2003), “Alterations in Brain and Immune Function Produced by Mindfulness Meditation", Psychosomatic Medicine, Vol. 65, pp. 564-570.

Del Re, A. C., Flückiger, C., Goldberg, S. B., and Hoyt, W. T. (2013), "Monitoring mindfulness practice quality: an important consideration in mindfulness practice", Psychotherapy Research, Vol. 3, No. 1, pp. 54-66.

Diener, E., Emmons, R. A., Larsen, R. J., and Griffin, S. (1985), “The Satisfaction with Life Scale”, Journal of Personality Assessment, Vol. 49, pp. 71-75. 
Diener, E., Lucas, R.E., and Oishi, S. (2002), Subjective Well-Being, Part V. Handbook of Positive Psychology, Oxford.

Fresco, D.M., Moore, T., van Dulmen et al., (2007), "Initial psychometric properties of the experiences questionnaires: Validation of a self-report measure of de-centering", Behavior Therapy, Vol. 36, pp.234-246.

Fullager, C.J. and Holloway, E.K. (2009), "Flow at work: An experience sampling approach”, Journal of Occupational and Organizational Psychology, Vol. 82, pp. 595-615.

Girden, E. R. (1992), “ANOVA: repeated measures”, Sage University Papers Series on Quantitative Applications in the Social Sciences, Vol. 84. Sage, Thousand Oaks, CA. Grossman, P., Niemann, L., Schmidt, S., and Walach, H. (2004), "Mindfulness-based stress reduction and health benefits: A meta-analysis", Journal of Psychosomatic Research, Vol. 57, pp. 35-43.

Grossman, P., Tiefenthaler-Gilmer, U., Raysz, A., and Kesper, U. (2007), “Mindfulness training as an intervention for fibromyalgia: Evidence of post-intervention and 3-year follow-up benefits in well-being”, Psychotherapy and Psychosomatics, Vol. 76, No. 4, pp. 226-233.

Grossman, P., Kappos, L., Gensicke, H., D’Souza, M., Mohr, D.C., Penner, IK., Steiner, C. (2010), "MS quality of life, depression and fatigue improve after mindfulness training: A randomized trial”, Neurology, Vol. 75, pp. 1141-1149.

Hölzel, B. K., Carmody, J., Vangel, M., Congleton, C., Yerramsetti, S. M., Gard, T., et al. (2011), "Mindfulness practice leads to increases in regional brain gray matter density”, Psychiatry Research: Neuroimaging, Vol. 191, pp. 36-43.

Hulsheger, U. R., Alberts, H. J. E. M., Feinholdt, A., and Lang, J. W. B. (2013), "Benefits of mindfulness at work: The role of mindfulness in emotion regulation, emotional exhaustion and job satisfaction", Journal of Applied Psychology, Vol. 98, No. 2, pp. 310-325.

Huppert, F. and Wittinghton, J.E. (2003), “Evidence for the independence of positive and negative well-being: Implications for quality of life assessment", British Journal of Health Psychology, Vol. 8, pp. 107-122.

Huppert, F. (2004), "Positive mental health in individuals and populations", Chapter 12, In The Science of Well-Being, Edited by Felicia Huppert, Nick Baylis and Barry Keverne. Oxford.

Jacob, B., and Nagel, L. (2003), “ The impact of a brief mindfulness-based stress reduction 
program on perceived quality of life", International Journal of Self-Help and SelfCare, Vol. 2 No. 2, pp. 155-168.

Jha, A. P., Stanley, E. A., Kiyonaga, A., Wong, L., and Gelfand, L. (2010), “Examining the protective effects of mindfulness training on working memory capacity and affective experience", Emotion, Vol. 10, No. 1, pp. 54-64.

Kabat-Zinn, J., (2003), "Mindfulness-based Interventions in context: Past, present, and future", Clinical Psychology, Vol. 10, No. 2, 144-156.

Kabat-Zinn, J., Lipworth, L., Burney, R., and Sellers, W. (1987), "Four year follow-up of a Meditation-Based Program for the Self-Regulation of Chronic Pain: Treatment Outcomes and Compliance", The Clinical Journal of Pain, Vol. 2, pp.159-173,

Keng, S.L., Smoski, M.J., Robins, C.J. (2011), "Effects of mindfulness on psychological health: A review of empirical studies", Clinical Psychology Review, Vol. 31, No 6, pp. 1041-1056.

Klatt, M. D., Buckworth, J., and Malarkey, W. B. (2009), "Effects of low-dose mindfulnessbased stress reduction (MBSR-ld) on working adults", Health Education and Behavior, Vol. 36, pp. 601-614.

Khoury, B., Lecomte, T., Fortin, G., Masse, M., Therien, P., Bouchard, V., et al. (2013), "Mindfulness based therapy: A comprehensive meta-analysis". Clinical Psychology Review, Vol.33, pp. 763-771.

Leary, M.R. (2004), The curse of the self: Self-awareness, egotism, and the quality of human life, Oxford University Press, New York, NY.

Luthans, F., Youssef, C,M., and Avolio, B.J. (2007), Psychological capital: Developing the human competitive edge, Oxford University Press, Oxford, UK,

Lutz, J., Herwig, U., Opialla, S., Hittmeyer, A., Jancke, L, Rufer, M., Holtforth, M.G. and Bruhl, A.B., (2014), "Mindfulness and emotion regulation - an fMRI study", SCAN, Vol. 9, pp. 776-785.

Patton, Q.M. (1990), Qualitative Evaluation and Research Methods, Sage Publications Inc., London.

Rosenberg, E. L. (2004), “Mindfulness and Consumerism”, In Kasser T. and Allen D.(Ed.), Psychology and consumer culture: The struggle for a good life in a materialistic world, American Psychological Association, Washington, DC, pp. 107-125.

Safran, J.D., and Segal, Z.V (1990), Interpersonal process in cognitive therapy, New York: Basic Books. 
Sauer, S. Walach, H., Smith, S., Hinterberger, T., Lynch, S. Bussing, A., and Kohls, N. (2013), "Assessment of mindfulness: Review on state of the art", Mindfulness, Vol. 4, pp. 3-17.

Sears, S., and Kraus, S. (2009). "I think therefore I am: Cognitive distortions and coping style as mediators for the effects of mindfulness meditation on anxiety, positive and negative affect, and hope", Journal of Clinical Psychology, Vol. 65, pp. 561-573.

Shapiro, S. L., Astin, J. A., Bishop, S. R., and Cordova, M. (2005), "Mindfulness-based stress reduction for health care professionals: Results from a randomized trial", International Journal of Stress Management, Vol. 12, pp.164-176.

Shapiro, S. L., Carlson, L. E., Astin, J. A., and Freedman, B. (2006), "Mechanisms of mindfulness", Journal of Clinical Psychology, Vol. 62, pp. 373-386.

Shapiro, S. L., and Izett, C. D. (2008). Meditation: A universal tool for cultivating empathy. In S. F. Hick \& T. Bien (Eds.), Mindfulness and the therapeutic relationship (pp. 161-175), Guilford Press, New York.

Sheldon, B (2011), Cognitive Behavioural Therapy: Research and practice in health and social care. $2^{\text {nd }}$ ed. Routledge, Oxon.

Snyder, C. R., Sympson, S. C., Ybasco, F. C., Borders, T. F., Babyak, M. A., and Higgins, R. L. (1996), "Development and validation of the State Hope Scale", Journal of Personality and Social Psychology, Vol.70, pp.321-335.

Snyder, C.R. (2002), "Hope theory: Rainbows in the mind", Psychological Inquiry, Vol. 13, No. 4, pp. 249-276.

Ulfberg, J., Carter, N., Talbäck, M., and Edling, C. (1996). "Excessive daytime sleepiness at work and subjective work performance in the general population and among heavy snorers and patients with obstructive sleep apnea", Chest, Vol. 110, pp. 659-663.

Van den Hurk, P. A. M., Giommi, F., Gielen, S. C., Speckens, A. E. M., and Barendregt, H. P. (2010), "Greater efficiency in attentional processing related to mindfulness meditation", The Quarterly Journal of Experimental Psychology, Vol. 63, pp. 11681180.

Virgili, M (2013), “Mindfulness-Based Interventions Reduce Psychological Distress in Working Adults: a Meta-Analysis of Intervention Studies”, Mindfulness, DOI 10.1007/s12671-013-0264-0.

Visted, E., Vollestad, J. Nielsen, M.B., and Nielsen, G.H. (2014), “The impact of groupbased mindfulness training on self-reported mindfulness: a systematic review and meta-analysis", Mindfulness, Vol. 6, pp. 501-522. 
Vollestad, J., Nielsen, M.B., and Nielsen, G.H. (2012), "Mindfulness and acceptance-based interventions for anxiety disorders: A systematic review and meta-analysis", British Journal of Clinical Psychology, Vol. 51, pp. 239-260.

Williams, M., and Penman, D. (2011), Mindfulness: A practical guide to finding peace in a frantic world, Piatkus, London.

Wilson, K.A., Chamblers, D.L., and de Beurs, E. (2004), “Beck Anxiety Inventory”, in Maruish, M.E. (Ed.), The use of psychometric testing for treatment, planning and outcomes assessment, Vol.3, Lawrence Erlbaum Associates, New York, pp. 399-420.

Youssef, C.M., and Luthans, F. (2007), "Positive Organizational Behavior in the Workplace: The impact of Hope, Optimism, and Resilience”. Journal of Management, Vol. 33, No. 5, pp-774-800. 